\title{
INDIRECT OPTICALLY CONTROLLED PSEUDOMORPHIC HEMT BASED MMIC OSCILLATOR
}

\author{
A. Bangert*, W. Benz, M. Berroth, A. Hülsmann, V. Hurm, G. Kaufel, \\ K. Köhler, J. Rosenzweig, Jo. Schneider
}

\section{ABSTRACT}

For the first time an indirect optically controlled monolithic integrated oscillator was fabricated and examined experimentally. The oscillator was designed for a frequency of about $7 \mathrm{GHz}$. By illuminating a $60 \times 60 \mu \mathrm{m}^{2}$ photodiode by the light of a pigtailed laser diode $(\lambda=840 \mathrm{~nm})$, the free-running frequency of the oscillator was tunable in a range of more than $7 \mathrm{MHz}$. A locking range of more than $3 \mathrm{MHz}$ was achieved. A phase shift in the output signal of nearly $180^{\circ}$ has been observed.

\section{INTRODUCTION}

At the present time, optical injection locking is a well known method to synchronise a great number of oscillators to the frequency of a master generator, e.g. for the use in phased-array antenna systems. Fundamentally, there are two different techniques that are distinguished by the way of injecting the locking signal into the circuit.

The technique is called direct when the active device of an oscillator, e.g. a silicon bipolar transistor [1], is illuminated by a modulated light source. The direct optical injection locking has been subject of many investigations with different kinds of devices as IMPATT [2], MESFET [3-4], MODFET [5-7], and recently HBT [8]. However, the direct method suffers from a low sensitivity of the 'optical detector'.

To overcome this problem one has to optimise the employed device or simply use a device that is primarily designed for the reception of optical signals: a photodetector. This is called the indirect optical injection locking technique [9]. The integration of an amplifier in such a circuit increases the locking range drastically [10]. Both, the direct and the indirect method, may be used to lock an oscillator to the harmonic or a subharmonic frequency.

In this paper, we present our experimental results on harmonic indirect optical injection locking, obtained with a monolithically integrated oscillator containing both, a pseudomorphic HFET and a metal-semiconductor-metal (MSM) photodiode.

Fraunhofer-Institut für Angewandte Festkörperphysik, Tullastr. 72, W-7800 Freiburg, Germany;

* is also with the Universität Kassel, Wilhelmshöher Allee 73, W-3500 Kassel, Germany 


\section{OSCILLATOR CIRCUIT}

A microphotograph of the realised monolithic integrated oscillator is shown in Fig. 1. The size of the circuit is less than $1 \times 1 \mathrm{~mm}^{2}$. The elements will be discussed below.
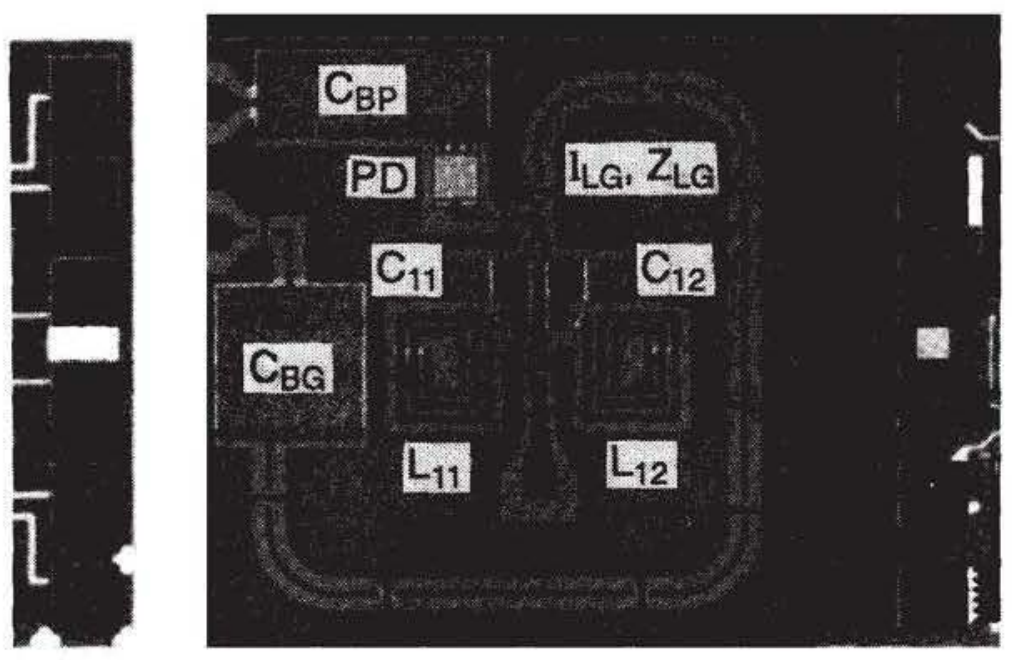

Fig. 1: Microphotograph of the MMIC oscillator.

The circuit diagram of the examined oscillator is depicted in Fig. 2. A pseudomorphic HEMT (25\% In in the channel) with a gate width of $\mathrm{w}_{\mathrm{g}}=2 \times 100 \mu \mathrm{m}$ and a gate length of $\mathrm{l}_{\mathrm{g}}=0.25 \mu \mathrm{m}$ was used as the active device [11]. A small capacitance $\left(C_{1}\right)$ and an inductor $\left(L_{1}\right)$ connected from source to ground serve as the mainly frequency determining elements. It can be seen from the photograph that the geometry of the transistor naturally splits these elements into two components. The gate bias voltage is connected via a coplanar line. At the drain electrode both, the drain bias voltage and the measurement equipment are connected via a coplanar line.

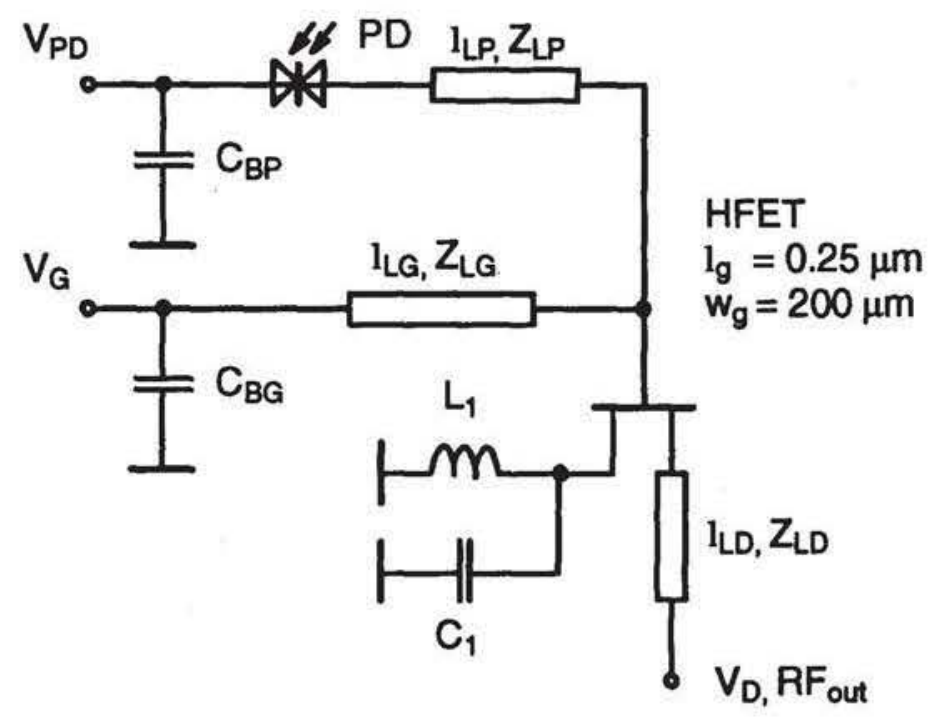

Fig. 2: Circuit diagram of the MMIC oscillator.

An MSM photodiode (PD) is used to convert the optical signal into an electrical one. The active area is $60 \times 60 \mu \mathrm{m}^{2}$. Two interdigitated comb electrodes are formed by $1 \mu \mathrm{m}$ wide fingers with a separation of $1.5 \mu \mathrm{m}$ between each. Fig. 3 shows the I-V-characteristic of the photodiode at different optical power levels $\mathrm{P}_{\text {opt }}$. The responsivity is around $0.25 \mathrm{~A} / \mathrm{W}$ for $5 \mathrm{~V}$ bias at a wavelength of $840 \mathrm{~nm}$. 


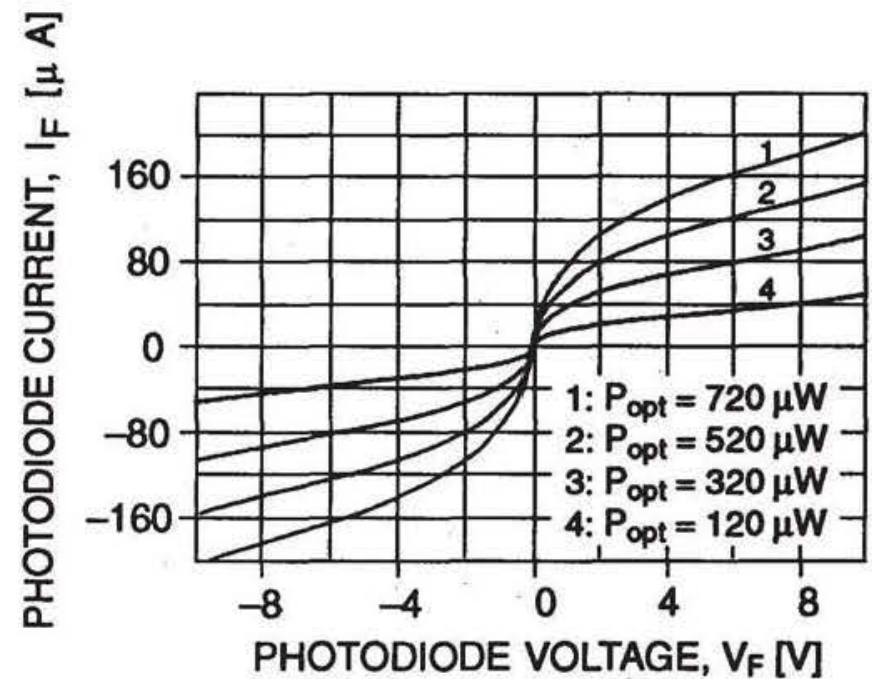

Fig. 3: I-V-characteristic of the MSM photodiode.

\section{EXPERIMENTAL SETUP AND RESULTS}

For observing both, the tuning and the locking behaviour, the described oscillator was measured on a wafer prober. Fig. 4 gives a block diagram of the setup used during the experiments. An rf generator is employed to modulate the optical output power of a semiconductor laser diode. Its light is led to the photodiode of the MMIC oscillator by an optical fibre. The oscillator is biased by three different power supplies (photodiode, gate, drain). The oscillator output is connected to a spectrum analyser and a digitizing oscilloscope to make analysis in frequency and time domain, respectively.

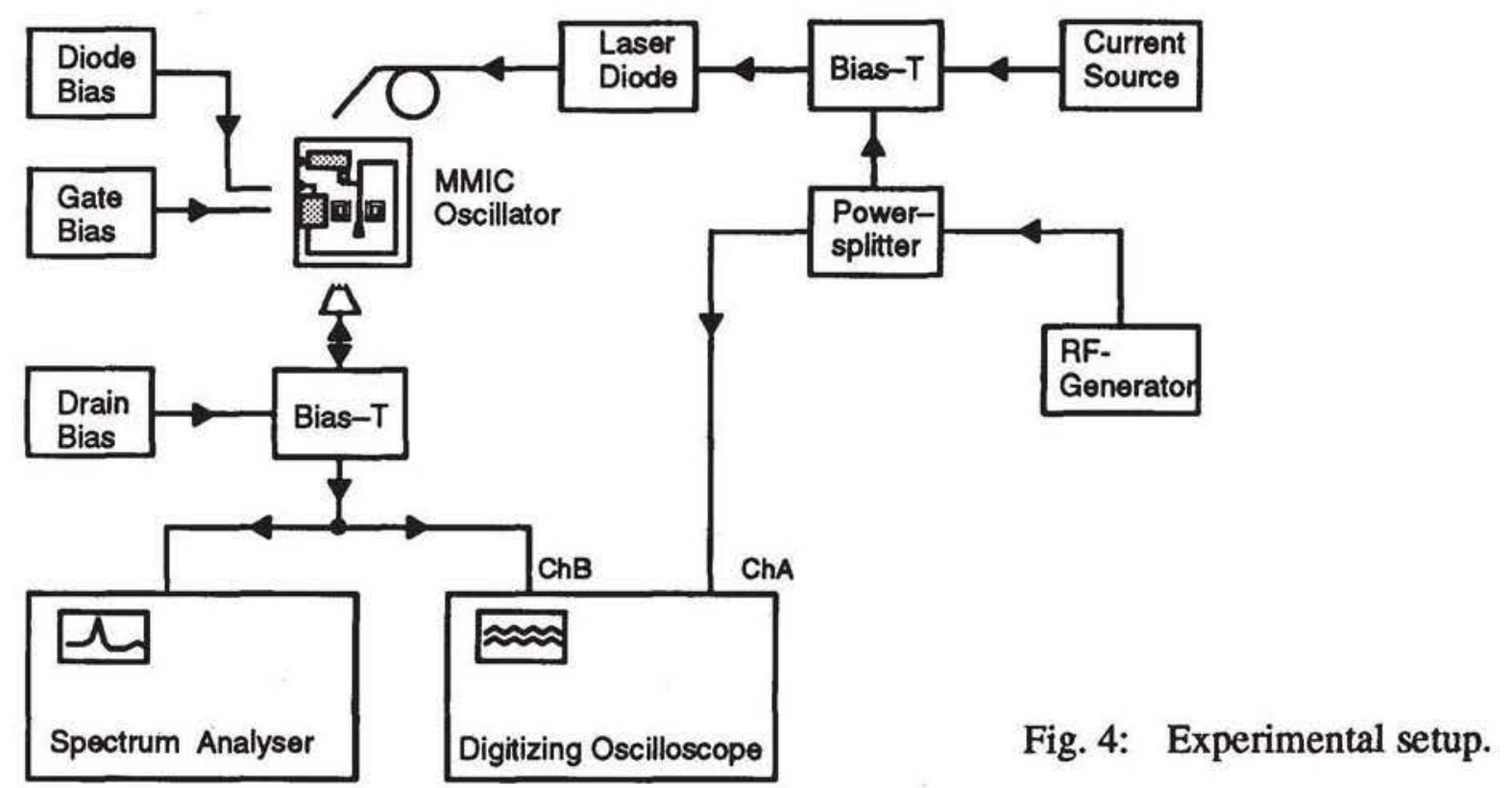

In the first part of the experiment, the tuning range of the oscillator was determined. The free-running frequency of the oscillator could be shifted by approximately $7 \mathrm{MHz}$ from the frequency in the dark by illuminating the photodiode by the unmodulated light of the laser diode $\left(\mathrm{P}_{\mathrm{opt}}=1 \mathrm{~mW}\right)$. 


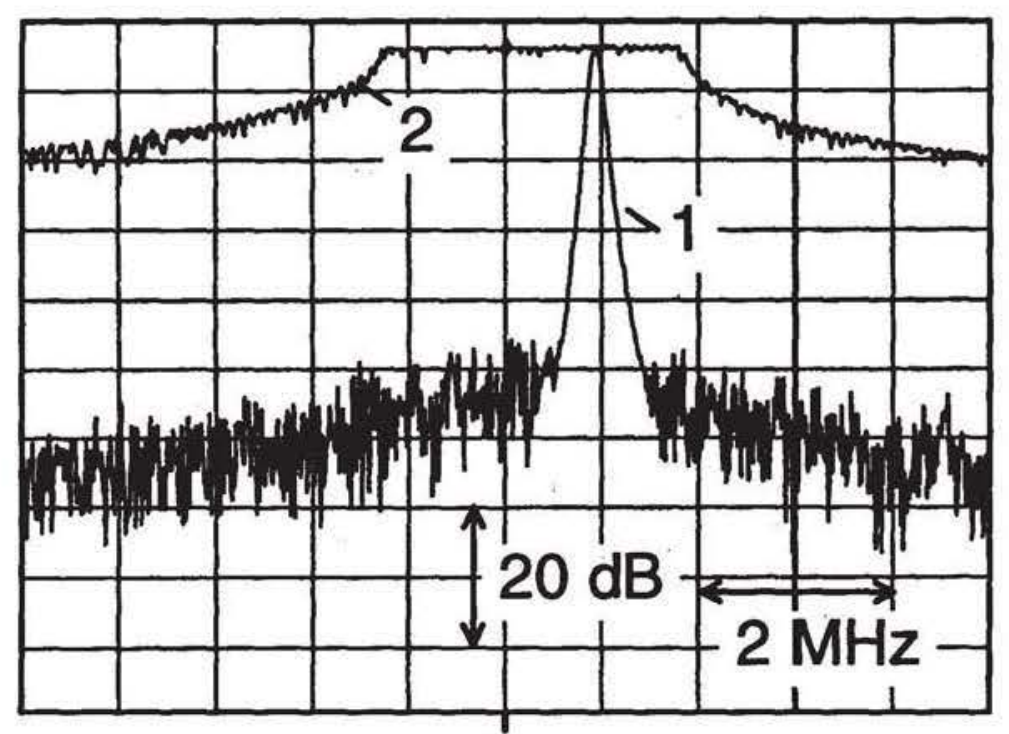

\section{$7.011 \mathrm{GHz}$}

Fig. 5: Locking range of the oscillator (1: locked oscillator, 2: locking range).

Secondly, the locking behaviour of the circuit was examined. The light of the laser was modulated by using an if generator. During the following experiments, the optical peak-to-peak laser power modulation was approximately $\mathrm{P}_{\text {opt } \mathrm{p}-\mathrm{p}} \approx 1 \mathrm{~mW}$. In the frequency domain, the locking range was determined by varying the frequency of the $\mathrm{rf}$ generator while the oscillator frequency was watched to be synchronised to the generator signal. The plateau in curve 2 of Fig. 5 shows the locking range. In the time domain, the phase of the locked oscillator output in relation to the generator signal was measured at different states of illumination. By the variation of the average incident light ('dc-light'), the free-running frequency of the oscillator was shifted, while the oscillator was locked to the constant generator frequency. In Fig. 6 the oscillator output is depicted in dependence of the average incident optical power $\mathrm{P}_{\mathrm{ave}}$. The comparison of the different curves shows pure signals with a maximum obtainable phase shift of $180^{\circ}$.

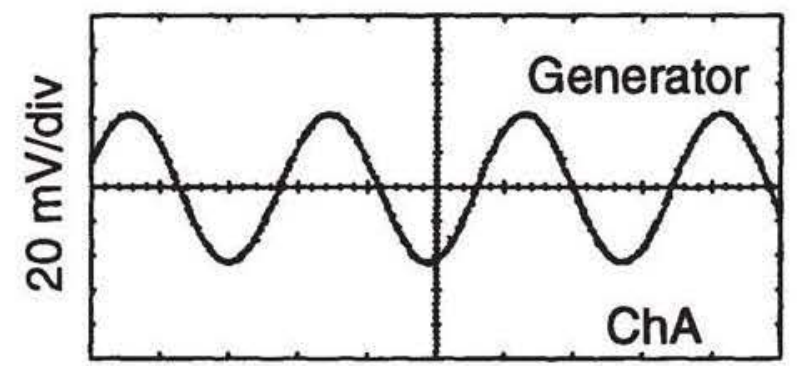

50 ps/div

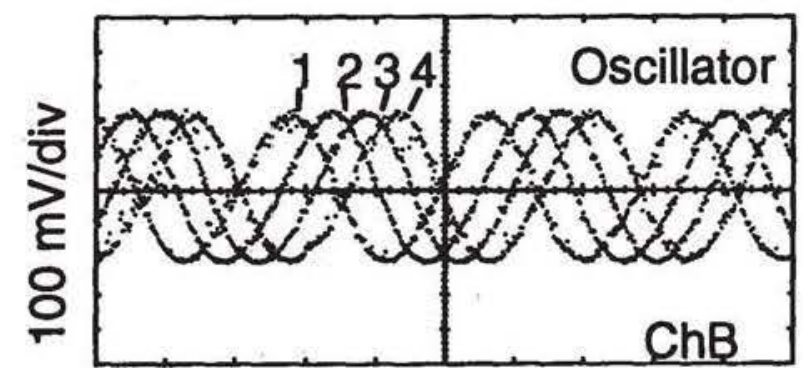

50 ps/div

Fig. 6: Generator signal (ChA) and oscillator output signal (ChB) at different levels of illumination (1: $\left.P_{\text {ave }}=850 \mu \mathrm{W}, 2: P_{\text {ave }}=770 \mu \mathrm{W}, 3: P_{\text {ave }}=620 \mu \mathrm{W}, 4: P_{\text {ave }}=550 \mu \mathrm{W}\right)$. 


\section{CONCLUSION}

The results presented above show the efficiency of indirect optically controlled MMIC oscillators. The indirect method for optical injection locking of oscillators is shown to be adequate and feasible. The implementation of a photodiode for the optical synchronisation in an MMIC leads to an easier connection of the fibre in later systems. Furthermore, there is no need for an especially trimmed HFET device for being an optical sensor, what that device normally is not intended to be.

\section{ACKNOWLEDGMENT}

The authors greatly acknowledge the continuous support by Prof. H. S. Rupprecht. Thanks are also due to T. Jakobus for his excellent technology management, W. Jeimke for drawing the figures, and J. Braunstein for assistance in the design of the circuit.

\section{REFERENCES}

[1] Yen H W, Barnoski M K, "Optical injection locking and switching of transistor oscillators", 1978, Appl. Phys. Lett., Vol 32, pp 182-184.

[2] Forrest JR, Seeds A J, "Optical injection locking of IMPATT oscillators", 1978, Electron. Lett., Vol 14, pp 626-627.

[3] Salles A A A de, "Optical control of GaAs MESFET's", 1983, IEEE Trans., Vol MTT-31, pp 812-820.

[4] Madjar A, Paollela A, Herczfeld P R, 'The GaAs MESFET as an optical control port on MMICproperties, limitations and guidelines", 1991, $21^{\text {st }}$ Europ. Microw. Conf. Worksh. Proc., pp 8-13.

[5] Simons R N, Bhasin K B, "Microwave performance of an optically controlled AlGaAs/GaAs high electron mobility transistor and GaAs MESFET", 1987, IEEE MTT-S Int. Microw. Symp. Dig., pp 815-818.

[6] Romero M A, Cunha A L A, Salles A A A de, "Theory and experiment for the HEMTs under optical illumination”, 1991, IEEE MTT-S Int. Microw. Symp. Dig., pp 495-498.

[7] Bangert A, Ludwig M,"A direct optical injection locked $8 \mathrm{GHz}$ MMIC oscillator", 1991, IEEE MTT-S Int. Microw. Symp. Dig., pp 499-502.

[8] Bangert A, Lauterbach T, "Initial observations of optical injection locking of oscillators using heterojunction bipolar transistors", 1992, Electron. Lett., Vol 28, pp 621-623.

[9] Saedi R, Daryoush A S, Berceli T, "Optically controlled $24 \mathrm{GHz}$ oscillator", 1990, Proc. of the $20^{\text {th }}$ Europ. Microw. Conf., pp 579-583.

[10] Daryoush A S, Herczfeld P R, "Indirect optical injection locking of multiple X-band oscillators", 1986, Electron. Lett., Vol 22, pp 133-134.

[11] Braunstein J, Tasker P, Kőhler K, Schweizer T, Hülsmann A, Schlechtweg M, Kaufel G, "Investigation of transport phenomena in pseudomorphic MODFETs", 1991, Int. Symp. GaAs and Related Compounds Dig., pp 161-166. 